\title{
Palonosetron plus single-dose dexamethasone for the prevention of nausea and vomiting in women receiving anthracycline/cyclophosphamide-containing chemotherapy: meta-analysis of individual patient data examining the effect of age on outcome in two phase III trials
}

\author{
Luigi Celio • Erminio Bonizzoni • Emilio Bajetta • \\ Silvia Sebastiani • Tania Perrone • Matti S. Aapro
}

Received: 30 January 2012 / Accepted: 23 July 2012 / Published online: 8 August 2012

(C) The Author(s) 2012. This article is published with open access at Springerlink.com

\begin{abstract}
Purpose Data from two randomized trials, evaluating a single-day regimen of palonosetron plus dexamethasone against emesis due to moderately emetogenic chemotherapy, were assessed for the impact of age on outcome in a pooled sample of women receiving anthracycline and/or cyclophosphamide (AC)-containing chemotherapy.
\end{abstract}

Presented in part at the MASCC/ISOO International Symposium, Athens, June 23-25, 2011

\section{Celio $(\varangle)$}

Medical Oncology Unit 1,

Fondazione IRCCS "Istituto Nazionale Tumori",

Via Venezian 1,

20133 Milan, Italy

e-mail: luigi.celio@istitutotumori.mi.it

\section{E. Bonizzoni}

Section of Medical Statistics and Biometry, University of Milan,

Milan, Italy

\section{E. Bajetta}

Policlinico di Monza, Istituto di Oncologia,

Monza, Italy

\section{S. Sebastiani}

Business Unit Oncology and Cancer Supportive Care,

Helsinn Healthcare SA,

Lugano, Switzerland

\section{T. Perrone}

Scientific Department, Italfarmaco S.p.A.,

Cinisello Balsamo, Italy

M. S. Aapro

Clinique de Genolier, Multidisciplinary Oncology Institute,

Genolier, Switzerland
Methods Chemo-naïve breast cancer patients randomized to receive palonosetron $(0.25 \mathrm{mg})$ plus dexamethasone $(8 \mathrm{mg}$ IV) on day 1 of chemotherapy $(n=200)$, or the same regimen followed by oral dexamethasone $(8 \mathrm{mg})$ on days 2 and $3(n=$ 205), were included in the analysis. The primary endpoint was complete response (CR: no vomiting and no rescue antiemetics) in the 5-day study period. The effect of the 1-day regimen and age ( $<50$ and $\geq 50$ years) was investigated by a meta-analysis of individual patient data.

Results Younger patients comprised $43 \%$ and $49 \%$ of the 1day and 3-day regimen groups, respectively; $94 \%$ of the pooled sample received the AC combination. There were no between-treatment differences in CR rate according to age during all observation periods. In the 1-day regimen group, $55.2 \%$ of younger patients achieved overall CR compared with $54 \%$ of older patients. In the 3-day regimen group, $51.5 \%$ of younger patients achieved overall CR compared with $58.7 \%$ of older patients. In the adjusted analysis, younger age was not associated with overall $\mathrm{CR}$ to treatment (risk difference, $-3.1 \%$; $95 \% \mathrm{CI},-13.0$ to $6.7 \%$; $P=0.533$ ).

Conclusions These results provide evidence that, irrespective of age, the dexamethasone-sparing regimen is not associated with a significant loss in overall anti-emetic protection in women undergoing AC-containing chemotherapy.

Keywords Palonosetron - Dexamethasone $\cdot \mathrm{CINV} \cdot$ Breast cancer $\cdot$ AC-containing chemotherapy $\cdot$ Meta-analysis

\section{Introduction}

Chemotherapy-induced nausea and vomiting (CINV) remains one of the most distressing side effects of 
cancer chemotherapy, in part because both treatmentrelated and patient-related risk factors need to be considered to ensure optimal CINV control for individual patients. The strongest of patient-related factors are generally assumed to be gender and age. Women have an increased risk of CINV, and patients less than 50 years old are also more likely than older patients to suffer from CINV [1]. Both female gender and younger age affect the intrinsic emetogenicity of the chemotherapy regimen that has been described as the most important risk factor for CINV [2]. Although agents such as cyclophosphamide and anthracyclines (doxorubicin and epirubicin) are individually considered as being moderately emetogenic, combinations of emetogenic agents may have additive effects on the overall emetogenicity of a regimen [2]. It has been recognized that women receiving the combination of an anthracycline and cyclophosphamide (AC) are at a particularly high risk of nausea and vomiting [3, 4].

The second-generation serotonin $\left(5-\mathrm{HT}_{3}\right)$-receptor antagonist palonosetron is the only agent in the class that was approved by the Food and Drug Administration for use in preventing delayed nausea and vomiting after single-day administration of moderately emetogenic chemotherapy (MEC) [5]. In a recently reported doubleblind, randomized phase III trial in patients undergoing either cisplatin or AC-containing chemotherapy, palonosetron plus dexamethasone for 3 days provided complete protection against delayed CINV that was superior to a single-dose of granisetron plus 3-day dexamethasone [6]. However, dexamethasone for prophylaxis of delayed emesis after MEC induces moderate-tosevere adverse effects that may have a substantial impact on the quality of life [7]. There is also an interest in reducing the dose of dexamethasone in certain clinical situations and/or in subsets of patients [8]. More recently, two similarly designed randomized phase III trials have evaluated the efficacy of a dexamethasonesparing regimen for prevention of acute and delayed CINV due to single-day MEC regimens [9, 10]. In one trial, the patient population consisted of women with breast cancer undergoing AC-containing chemotherapy, while patients with solid tumors undergoing a broad range of MEC regimens were enrolled into the second trial. In both studies, palonosetron plus a singledose of dexamethasone provided complete protection against CINV (primary endpoint) which was non-inferior to that of palonosetron plus 3-day dexamethasone in the overall 5-day study period.

The purpose of this retrospective post hoc analysis was to assess the impact of age on prevention of CINV in the pooled data set of women with breast cancer undergoing anthracycline and/or cyclophosphamide-containing chemotherapy.

\section{Patients and methods}

Study design

A pre-specified retrospective analysis was conducted using individual patient data from women with breast cancer receiving specific chemotherapy regimens who were enrolled in two multicenter, randomized, phase III, comparative trials. Both studies tested the non-inferiority of a single-day regimen of palonosetron and dexamethasone, compared with the same regimen on day 1 followed by dexamethasone on days 2 and 3, for the prevention of acute and delayed CINV after the first cycle of chemotherapy. Detailed descriptions of the design (including eligibility criteria) and primary efficacy and tolerability results of these studies have been reported elsewhere $[9,10]$. Both studies had local institutional review board approval and written informed consent was obtained when patients entered each individual trial.

\section{Patients and treatment}

Chemo-naïve women, aged $\geq 18$ years old with histologically confirmed breast cancer, scheduled to receive a single dose of intravenous anthracycline (doxorubicin $\leq 60 \mathrm{mg} / \mathrm{m}^{2}$ or epirubicin $\leq 100 \mathrm{mg} / \mathrm{m}^{2}$ ) and/or cyclophosphamide $\left(<1,500 \mathrm{mg} / \mathrm{m}^{2}\right.$ on day 1$)$, were eligible for enrolment. Additional chemotherapeutic agents of Hesketh emetogenic level 2 or lower could be added to the above regimens [2]. All patients had an adequate Eastern Cooperative Oncology Group (ECOG) performance status of 0,1 , or 2 . In both studies, regardless of assignment to either study arm, all patients received a single intravenous dose of palonosetron $(0.25 \mathrm{mg})$ as a bolus given $30 \mathrm{~min}$ before initiation of chemotherapy on day 1 . Administration of prophylactic dexamethasone ( $8 \mathrm{mg}$ intravenously) before the initiation of chemotherapy on day 1 was also required. Patients were randomly assigned to receive one of two delayed anti-emetic regimens: no additional treatment (1-day regimen) or dexamethasone ( $8 \mathrm{mg}$ orally) on days 2 and 3 (3-day regimen). After chemotherapy, rescue medication for treatment of nausea and vomiting was permitted on an as-needed basis.

\section{Assessments}

Patients made daily entries in their diary for 5 days after starting chemotherapy to record emetic events and severity of nausea in the previous $24 \mathrm{~h}$, as well as any use of rescue medication. The primary efficacy endpoint of both studies was the proportion of patients with complete response (CR; defined as no emetic episodes and no rescue anti-emetics) during the overall 5-day study period after the first cycle of chemotherapy. 
A modified intention-to-treat analysis was conducted, including all women who received chemotherapy, took the study medication, and completed the follow-up period (days 1-5 following the initiation of chemotherapy). The post hoc analysis was conducted on the pre-specified endpoint of $\mathrm{CR}$ during the overall 5-day study period. The impact of the 1-day regimen on $\mathrm{CR}$ and on age as a prespecified baseline risk factor ( $<50$ years, $\geq 50$ years) for CINV was investigated [1]. Treatment effects were also estimated within each age category for the acute $(0-24 \mathrm{~h})$ and the delayed (24-120 h) time periods. Secondary efficacy endpoints of no vomiting and no nausea were also assessed.

\section{Statistical analysis}

Individual patient data for randomly assigned women with breast cancer undergoing specific chemotherapy regimens were included in the pooled analysis. A meta-analysis of individual patient data was performed using the $\mathrm{CR}$ in the overall 5-day study period as dependent variable [11]. A generalized mixed linear model with study and treatment group as dummy-fixed effect was implemented with binomial distribution, identity link function (non-canonical link function) and heterogeneity (non constant) within study variance. The treatment-by-study interaction was planned to be added to the original model (fixed-effect meta-analysis) as an additional random effect in order to investigate and adjust estimates for the heterogeneity across studies (random-effect meta-analysis). The treatment-by-study interaction was considered statistically significant if the $P$ value was $\leq 0.10$. Since the random-effect model did not converge, the between-group difference with its associated $95 \%$ confidence interval (CI) was estimated using only the fixed-effect model. The effect of age on treatment outcome was evaluated using an extension of the original model with age as a subject-level covariate. Results were reported as risk differences (RDs) that allowed a straightforward comparison between the twosided $95 \% \mathrm{CI}$ of the between-group difference in CR to anti-emetic treatment for testing the non-inferiority hypothesis of the 1-day regimen (preset threshold of a $-15 \%$ difference between groups in both original studies) $[9,10]$.

Fisher's exact test was used to compare proportions of the other categorical variables. These secondary analyses were evaluated in an explorative or descriptive manner, and therefore no adjustment for multiplicity was applied. All $P$ values were two-sided, and a $P<0.05$ was considered statistically significant. All statistical analyses were performed using SAS software (version 9.1; SAS Institute, Cary, NC).

\section{Results}

Patient population

Of the 632 patients from the intention-to-treat populations in the two clinical studies, all randomly assigned 405 women $(64.1 \%)$ with breast cancer undergoing anthracycline and/or cyclophosphamide-containing chemotherapy were evaluable and included in the analysis. Among the evaluable patients, $188(46.4 \%)$ were younger than 50 years $(43.5 \%$ in 1 -day regimen and $49.3 \%$ in 3-day regimen). Patient demographic and baseline characteristics were similar between the dexamethasone-sparing and comparator groups (Table 1). The mean age for the pooled sample was 51 years (range, 26 to 78 years), and the vast majority of the study population $(78.5 \%)$ had a history of light or no alcohol consumption. Ninety-four percent of the pooled sample received a combination of $\mathrm{AC}$ for their chemotherapy regimen.

Primary outcome

The proportion of patients in the individual studies and pooled sample achieving CR during all time periods is

Table 1 Baseline characteristics of the pooled population by treatment group

\begin{tabular}{|c|c|c|c|c|}
\hline \multirow[t]{2}{*}{ Characteristic } & \multicolumn{4}{|c|}{$\%$ of patients } \\
\hline & & $\begin{array}{l}\text { Palo plus } \\
\text { 1-day Dex } \\
(n=200)\end{array}$ & & $\begin{array}{l}\text { Palo plus } \\
\text { 3-day Dex } \\
(n=205)\end{array}$ \\
\hline Female & & 100 & & 100 \\
\hline \multicolumn{5}{|l|}{ Age, years } \\
\hline Mean & 51.7 & & 51.3 & \\
\hline Standard deviation & 10.5 & & 10.5 & \\
\hline Race, white & & 100 & & 100 \\
\hline Primary tumor, breast & & 100 & & 100 \\
\hline ECOG PS 0-1 & & 100 & & 100 \\
\hline Stage of disease, early & & 100 & & 100 \\
\hline \multicolumn{5}{|l|}{ Alcohol consumption } \\
\hline Never & & 56.0 & & 51.7 \\
\hline Rarely & & 12.0 & & 11.2 \\
\hline Occasionally & & 10.5 & & 15.6 \\
\hline Regularly & & 7.5 & & 7.8 \\
\hline Missing & & 14.0 & & 13.7 \\
\hline \multicolumn{5}{|l|}{ Chemotherapy regimen } \\
\hline AC-based & & 93.0 & & 94.6 \\
\hline $\mathrm{CMF}$ & & 7.0 & & 5.4 \\
\hline
\end{tabular}

Palo plus dex palonosetron plus dexamethasone, ECOG PS Eastern Cooperative Oncology Group performance status, $A C$ anthracycline (doxorubicin or epirubicin) plus cyclophosphamide, $C M F$ cyclophosphamide plus methotrexate plus fluorouracil 
presented in Table 2. The CR data from the individual studies showed that the direction of the treatment effect was similar between treatment groups during the acute, delayed, and overall time periods. In the pooled analysis, the overall CR rate was $54.5 \%$ (95\% CI, $47.3 \%$ to $61.5 \%)$ in patients receiving the 1-day regimen and $55.1 \%(95 \%$ CI, $48 \%$ to $62.1 \%$ ) in those receiving the 3-day regimen, with a between-treatment RD of $-0.5 \%(95 \% \mathrm{CI},-10.3 \%$ to $9.3 \%$ ). Therefore, the non-inferiority hypothesis of the 1day regimen was confirmed, as the lower boundary of the $95 \% \mathrm{CI}$ of the $\mathrm{RD}$ with the 3-day regimen was greater than the preset threshold of $-15 \%$ difference.

Figure 1 shows the proportion of patients with CR in all three observation periods, by age and treatment group. There were no statistically significant between-treatment differences in $\mathrm{CR}$ rate according to the age categories during all three time periods. For the overall time period, no incremental improvement was observed with additional dexamethasone doses (i.e., the between-treatment difference) in the subgroup of younger patients, while the improvement was of only small magnitude (approximately $5 \%$ ) in the subgroup of older patients. As expected, the incremental improvement observed with additional dexamethasone doses was also of greater magnitude among older patients (10\%) compared with that seen among younger patients $(3 \%)$ in the delayed time period.

The first-order interaction of overall CR between antiemetic treatment and age was not statistically significant, providing no evidence for a differential treatment benefit on overall CR by age. In the adjusted analysis, age was not associated with worse outcome in terms of overall CR to anti-emetic treatment ( $<50$ vs. $\geq 50$ years: RD $-3.1 \%$; $95 \%$ $\mathrm{CI},-13.0$ to $6.7 \% ; P=0.533)$. Since the lower boundary of the $95 \% \mathrm{CI}$ for the RD from the 3-day regimen was greater than the preset threshold of $-15 \%$ difference (1-day vs. 3day: RD $-0.7 \%$; $95 \% \mathrm{CI},-10.6$ to $9.1 \%$ ), the noninferiority hypothesis of the 1-day regimen was also demonstrated after adjusting for age.

\section{Secondary outcomes}

Subset analyses of each treatment group by age were done for the secondary efficacy endpoints during all three observation periods (Table 3 ). In the pooled sample, across both treatment groups and at all time periods, the proportion of patients with no vomiting was high $(>70 \%)$, and there was no evidence of a differential treatment-group benefit. However, in the delayed time period, $12 \%$ lower vomiting control was observed among older patients following the 1-day regimen, when compared with older ones following the 3-day regimen ( $77 \%$ vs. $89.4 \% ; P=0.018$ ).

The proportion of patients with no nausea in either treatment group was similar for both the pooled sample and the subgroup of younger patients at any time period, while there was a trend toward improved control of nausea in older patients following the 3-day regimen compared with those following the 1-day regimen in the delayed and overall time periods (delayed, $41.6 \%$ vs. $53.8 \% ; P=0.078$; overall, $32.7 \%$ vs. $46.1 \% ; P=0.052$ ).

Table 2 Complete response (defined as no emetic episodes and no rescue anti-emetics) rates in all time periods by individual studies and treatment group

Complete responses

Palo plus 1-day Dex, $n / N(\%) \quad$ Palo plus 3-day Dex, $n / N(\%) \quad{ }^{\mathrm{a}}$ Risk difference between groups $(95 \% \mathrm{CI}), \%$

Acute phase $(0-24 \mathrm{~h})$

Aapro et al. [9]

$105 / 151(69.5)$

$40 / 49(81.6)$

Celio et al. [10]

All

$145 / 200(72.5)$

Delayed phase $(24-120 \mathrm{~h})$

Aapro et al.

$94 / 151(62.3)$

Celio et al.

$29 / 49(59.2)$

All

$123 / 200(61.5)$

Overall phase $(0-120 \mathrm{~h})$

Aapro et al.

Celio et al.

$81 / 151(53.6)$

$28 / 49(57.1)$

All

$$
\begin{gathered}
102 / 149(68.5) \\
40 / 56(71.4) \\
142 / 205(69.3) \\
\\
98 / 149(65.8) \\
42 / 56(75) \\
140 / 205(68.3) \\
\\
80 / 149(53.7) \\
33 / 56(58.9) \\
113 / 205(55.1)
\end{gathered}
$$

$$
\begin{array}{r}
1.1(-9.4,11.6) \\
10.2(-6.0,26.4) \\
3.8(-5.1,12.7) \\
-3.5(-14.4,7.4) \\
-15.8(-33.9,2.2) \\
-6.8(-16.2,2.5) \\
0.0(-11.4,11.3) \\
-1.8(-20.9,17.4) \\
-0.5(-10.3,9.3)^{\mathrm{b}}
\end{array}
$$

Palo plus dex palonosetron plus dexamethasone, $n$ number of complete responses, $N$ number of patients, $C I$ confidence interval

${ }^{a}$ One-day minus 3-day regimen with $95 \%$ CI obtained using individual patient meta-analysis for the overall study cohort

${ }^{\mathrm{b}}$ Non-inferiority hypothesis in primary analysis was demonstrated as the lower boundary of the $95 \%$ CI of risk difference greater than the preset threshold $(-15 \%)$ 

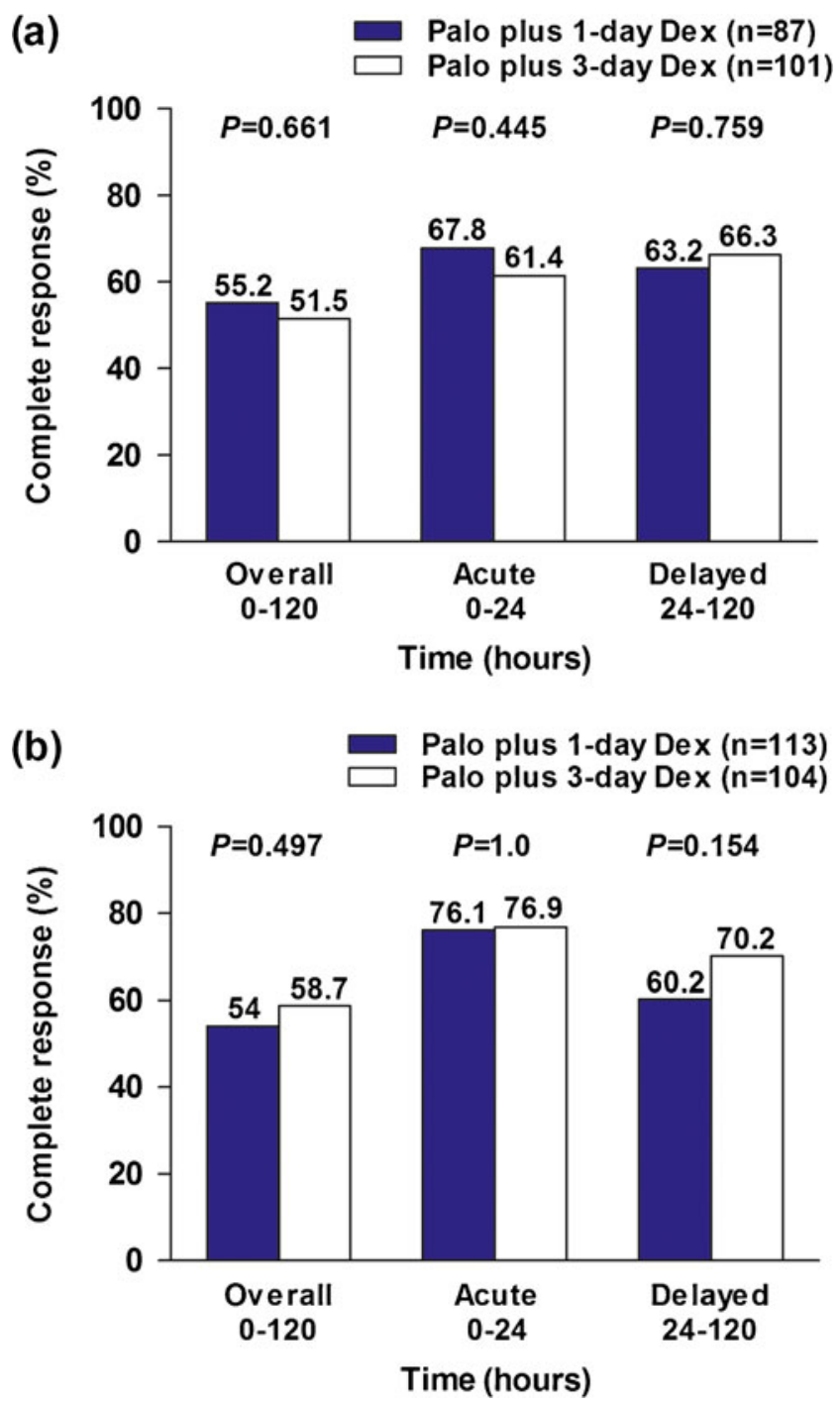

Fig. 1 Proportion of patients with complete response (no emesis, and no rescue anti-emetics) in the acute, delayed, and overall time periods, by age and treatment group. a Patients younger than 50 years. b Patients 50 years or older. palo plus dex palonosetron plus dexamethasone. $P$ values calculated by two-sided Fisher's exact test (1-day vs. 3-day)

Figure 2 shows the frequency of no vomiting and no nausea during the 5 days post-chemotherapy, by age and treatment group. Among the younger patients in each treatment group, a trend for higher control of vomiting and nausea was maintained with a clear increase of protection from days 1 to 5 . The rates of no vomiting or no nausea were higher among older patients in both treatment groups, but CINV control reached a plateau between days 2 and 3 in patients receiving dexamethasone only on day 1 . Significantly lower rates of older patients following the 1-day regimen were free of vomiting on days 2 and 3 compared with those following the 3-day regimen (day 2, $84.9 \% \mathrm{vs}$. $96.2 \% ; P=0.006$; day $3,86.7 \%$ vs. $99.0 \% ; P=0.0004$ ). Similarly, the proportion of older patients free of nausea was lower in the 1-day treatment group than in the 3-day treatment group over the 5 days post-chemotherapy, with the differences reaching statistical significance on day $3(55.8 \%$ vs. $73.1 \% ; P=0.011$ ).

\section{Discussion}

An approach based upon not only the emetogenicity of chemotherapy but also known risk factors would be desirable to tailor the anti-emetic regimen to individual patients. We assessed pooled data from two phase III studies to investigate the potential effect of age on outcome of a dexamethasone-sparing regimen in women with breast cancer undergoing a highly emetogenic AC combination [9, 10]. The retrospective post hoc analysis described here yielded two key findings: (1) the non-inferiority hypothesis of palonosetron plus single-dose dexamethasone could be confirmed in an adjusted model studying the influence of age and (2) an age younger than 50 years was not an independent predictor for poorer outcome in terms of overall $\mathrm{CR}$ to anti-emetic treatment.

The finding that the non-inferiority of the 1-day regimen was confirmed even after adjustment for age is of particular interest as it was obtained in a homogeneous cohort of female patients receiving a very uniform emetogenic stimulus, and further demonstrates the clinical value of palonosetron plus single-dose dexamethasone in this high-risk population [9].

Another key finding of this study is that an age less than 50 years was not significantly associated with overall CR to anti-emetic treatment in an adjusted analysis. In spite of the relatively small sample size, the more likely explanation for this finding is that age was an unimportant predictor in this analysis because of the modest impact of additional dexamethasone doses on treatment outcome in this cohort of patients. In an exploratory analysis, inclusion of dexamethasone on days 2 and 3 after the initiation of chemotherapy revealed a different emetic risk profile between the age subgroups in the delayed time period. Among younger patients, both vomiting and nausea control rates were similar between treatment groups with a clear increase of protection from days 1 to 5 . This finding suggests that the unique mechanism of action for palonosetron may at least in part neutralize the impact of additional dexamethasone in this subgroup at potentially higher risk. It is also interesting to observe that inter-individual variations concerning the metabolism of endogenous cortisol have been reported to contribute to the individual risk profile for CINV [12]. In addition, in ovarian cancer patients receiving cisplatin-based chemotherapy dexamethasone added to the anti-emetic effect of ondansetron primarily in women with lower basal urinary excretion of cortisol [13]. Since younger individuals 
Table 3 Results of pooled analysis of no vomiting and no nausea for all time periods, by age and treatment group

\begin{tabular}{|c|c|c|c|}
\hline & Palo plus 1-day Dex, $n / N(\%)$ & Palo plus 3-day Dex, $n / N(\%)$ & ${ }^{\mathrm{a}}$ Risk difference between groups $(95 \% \mathrm{CI}), \%$ \\
\hline \multicolumn{4}{|l|}{ No vomiting } \\
\hline \multicolumn{4}{|c|}{ Acute phase $(0-24 \mathrm{~h})$} \\
\hline All & $164 / 200(82)$ & $162 / 205(79)$ & $3.0(-4.7,10.7)$ \\
\hline$<50$ years & $67 / 87(77)$ & $70 / 101(69.3)$ & $7.7(-5.0,20.4)$ \\
\hline$\geq 50$ years & $97 / 113(85.8)$ & $92 / 104(88.5)$ & $-2.6(-11.5,6.3)$ \\
\hline \multicolumn{4}{|c|}{ Delayed phase $(24-120 \mathrm{~h})$} \\
\hline All & $161 / 200(80.5)$ & $177 / 205(86.3)$ & $-5.8(-13.1,1.4)$ \\
\hline$<50$ years & $74 / 87(85.1)$ & $84 / 101(83.2)$ & $1.9(-8.6,12.4)$ \\
\hline$\geq 50$ years & $87 / 113(77)$ & 93/104 (89.4) & $-12.4(-22.4,2.4)^{*}$ \\
\hline \multicolumn{4}{|c|}{ Overall phase $(0-120 \mathrm{~h})$} \\
\hline All & $144 / 200(72)$ & $149 / 205(72.7)$ & $-0.7(-9.4,8.0)$ \\
\hline$<50$ years & $61 / 87(70.1)$ & $65 / 101(64.4)$ & $5.7(-7.7,19.2)$ \\
\hline$\geq 50$ years & $83 / 113(73.5)$ & $84 / 104(80.8)$ & $-7.3(-18.5,3.9)$ \\
\hline \multicolumn{4}{|l|}{ No nausea } \\
\hline \multicolumn{4}{|c|}{ Acute phase (0-24 h) } \\
\hline All & $103 / 200(51.5)$ & $103 / 205(50.2)$ & $1.3(-8.5,11.0)$ \\
\hline$<50$ years & $38 / 87$ (43.7) & 39/101 (38.6) & $5.1(-9.0,19.2)$ \\
\hline$\geq 50$ years & $65 / 113(57.5)$ & $64 / 104(61.5)$ & $-4.0(-17.1,9.1)$ \\
\hline \multicolumn{4}{|c|}{ Delayed phase $(24-120 \mathrm{~h})$} \\
\hline All & $80 / 200(40)$ & $95 / 205(46.3)$ & $-6.3(-15.9,3.3)$ \\
\hline$<50$ years & 33/87 (37.9) & 39/101 (38.6) & $-0.7(-14.6,13.3)$ \\
\hline$\geq 50$ years & $47 / 113(41.6)$ & $56 / 104(53.8)$ & $-12.2(-25.6,1.0)$ \\
\hline \multicolumn{4}{|c|}{ Overall phase $(0-120 \mathrm{~h})$} \\
\hline All & $63 / 200(31.5)$ & $74 / 205(36.1)$ & $-4.6(-13.8,4.6)$ \\
\hline$<50$ years & 26/87 (29.9) & 26/101 (25.7) & $4.1(-8.7,16.9)$ \\
\hline$\geq 50$ years & $37 / 113(32.7)$ & $48 / 104(46.1)$ & $-13.4(-24.4,0.4)$ \\
\hline
\end{tabular}

Palo plus dex palonosetron plus dexamethasone, $n$ number of responders, $N$ number of patients, $C I$ confidence interval

${ }^{a}$ One-day minus 3-day regimen with $95 \% \mathrm{CI}$ obtained from the individual patient meta-analysis

* $P=0.018$ (two-sided Fisher's exact test [1-day vs. 3-day])

tend to have lower cortisol levels than older subjects [14], we speculate that differences in endogenous cortisol secretion can partly explain the age variations in risk for CINV. Therefore, our findings in the subgroup of younger patients probably reflect the very modest impact of additional dexamethasone doses on anti-emetic control in individuals who generally have low total exposure to endogenous cortisol. As expected, for the delayed time interval, there were lower control rates of both vomiting and nausea among older patients receiving single-dose dexamethasone, when compared with older patients receiving dexamethasone for 3 days. In the face of age-related increases in total exposure to endogenous cortisol, we suggest that further improvement in control of delayed CINV in older patients following the 3day regimen may be likely due to the effect of additional dexamethasone doses primarily in old women with relatively lower cortisol levels. Clinical investigations addressing relationship between patient's corticosteroid milieu and anti- emetic efficacy of dexamethasone in patients undergoing emetogenic chemotherapy should be conducted to substantiate these hypotheses.

It should be kept in mind that approximately $40 \%$ of women with breast cancer is over the age of 65 years [15], and the increased age generally puts them in a lower risk category for CINV [1]. However, older patients warrant particular attention in the selection of an anti-emetic regimen because older age is associated with decreased drug metabolism and clearance and increased co-morbidity which, coupled with increased frequency of poly-pharmacy, greatly increases the risk of unwanted drug interactions [16]. In spite of the potential for lower control rates of delayed symptoms among older patients receiving 1-day dexamethasone dosing, several observations indicate that our results may support clinicians who desire to tailor the therapy in these patients by reducing the overall exposure to dexamethasone. In the exploratory evaluation of daily occurrence of symptoms, the rates of older 
(a)

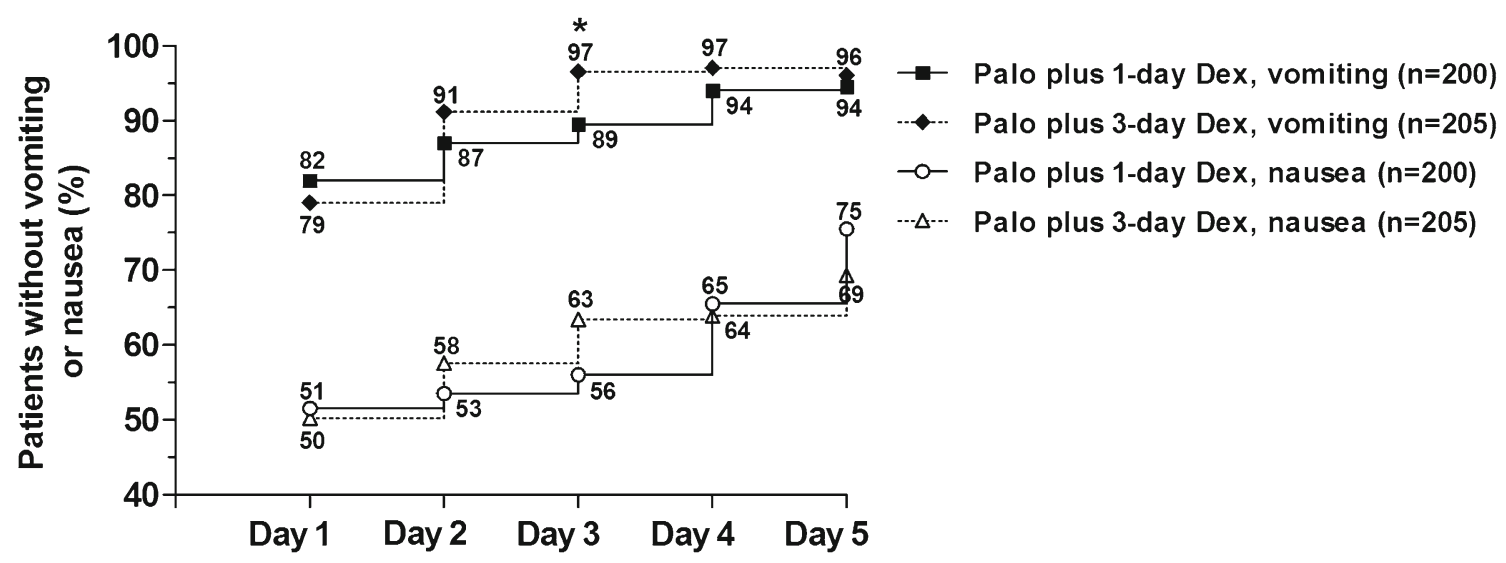

(b)

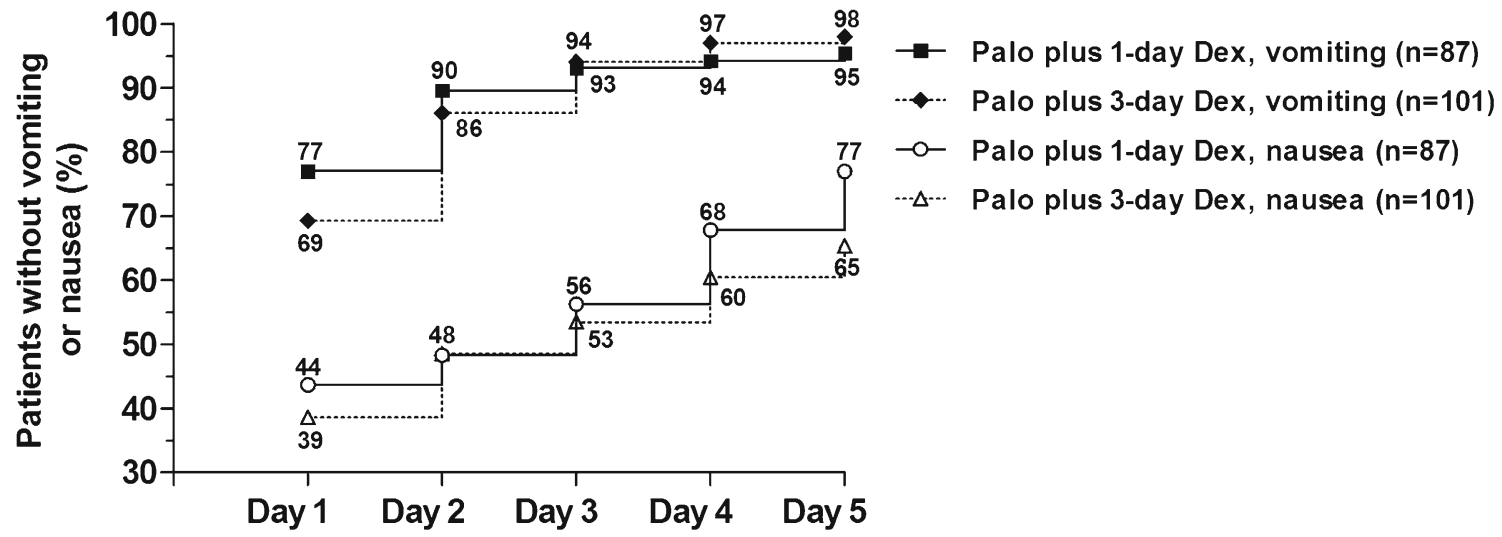

(c)

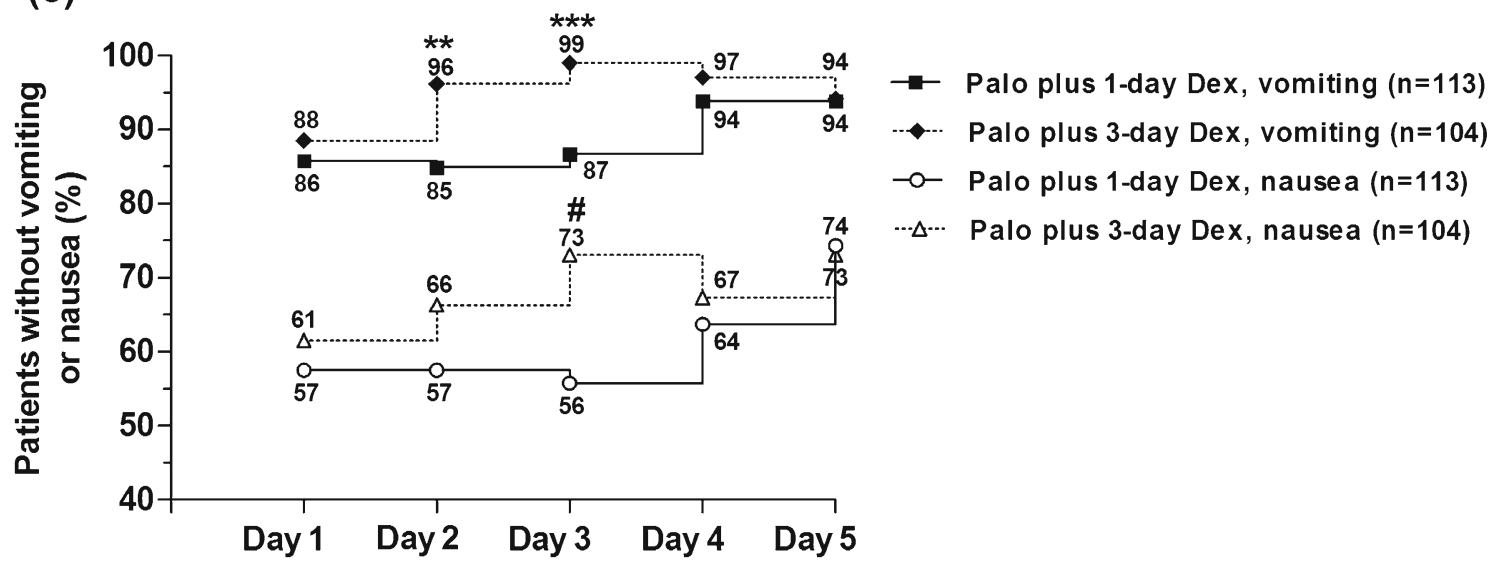

Fig. 2 Frequency of no vomiting and no nausea during the 5-day period after chemotherapy, by age and treatment group. a Overall population. b Patients younger than 50 years. c Patients 50 years or

patients with no vomiting or no nausea receiving palonosetron plus single-dose dexamethasone were high ( $\geq 85 \%$ for vomiting control and $>55 \%$ for nausea control) and maintained from days 1 to 5, suggesting that it is difficult to accurately evaluate the clinical impact of the differences compared with older older. palo plus dex palonosetron plus dexamethasone. ${ }^{*} P=0.006$ (two-sided Fisher's exact test [1-day vs. 3-day]). $* * P=0.006 ; * * * P=$ 0.0004; $\# P=0.011$ patients receiving the 3-day regimen. In spite of the intrinsic limitations of inter-study comparisons, a post hoc analysis of a large phase III trial in a similar population of breast cancer patients undergoing AC-containing chemotherapy randomized to either a triple regimen, including the NK-1 receptor 
antagonist aprepitant, or a control regimen (single-dose dexamethasone plus 3-day ondansetron), appears to support this interpretation [17]. Although no data concerning the incidence of no nausea were available for the aprepitant study, when compared with the efficacy results of the triple regimen by age the overall proportion of older patients with no vomiting in the palonosetron and 1-day dexamethasone group was consistent with that seen among older patients ( $\geq 55$ years) receiving aprepitant for 3 days ( $73 \%$ vs. $79 \%$ ). Likewise, the overall proportion of younger patients with no vomiting in the palonosetron and 1-day dexamethasone group was consistent with the results observed among younger patients ( $<55$ years) receiving aprepitant for 3 days (70 \% vs. $73 \%$ ). It also should be noted that optimal nausea control remains an unmeet need in CINV research and the NK-1 receptor antagonists have not been shown to be effective in improving nausea control in patients receiving AC-containing chemotherapy $[8,18]$.

Current guidelines recommend a triple regimen consisting of a 5- $\mathrm{HT}_{3}$-receptor antagonist plus dexamethasone and an NK-1 receptor antagonist for the prevention of CINV due to the combination of $\mathrm{AC}[3,4,19]$. However, if an NK-1 antagonist is not available, women undergoing $\mathrm{AC}$ containing chemotherapy should receive palonosetron plus 3-day dexamethasone [3]. Our findings indicate that, irrespective of age, the 1-day regimen offers high and similar overall control of symptoms as the 3-day regimen in this population.

One limitation of this analysis is that we were unable to assess the impact of age in an adjusted model including terms for other possible risk factors for CINV in breast cancer patients $[17,20]$. Very few patients in the pooled sample consumed alcohol regularly, while no data were collected on other risk factors in the individual trials. A second limitation of our study is that all patients had earlystage disease and an excellent performance status. However, since AC-containing regimens are the mainstay of adjuvant chemotherapy for breast cancer and the majority of patients undergo adjuvant therapy, the present findings should have widespread applicability.

This post hoc analysis confirms the non-inferiority of palonosetron plus single-dose dexamethasone for the prevention of CINV associated with the highly emetogenic combination of $\mathrm{AC}$ in breast cancer patients, even after adjusting for the influence of age. The current findings also indicate that younger age does not predict decreased efficacy in terms of overall $\mathrm{CR}$ to the dexamethasone-sparing regimen. Therefore, it is reasonable to conclude that tailoring dexamethasone dosing to reduce exposure in women treated with palonosetron on day 1 is not associated with a clinically significant loss in anti-emetic protection during the 5-day observation period. Since a triple regimen including aprepitant is the guideline-recommended treatment in the setting of $\mathrm{AC}$ - containing chemotherapy and no randomized data about palonosetron plus aprepitant are still available, additional randomized studies of the dexamethasone-sparing regimen with or without aprepitant to separate the anti-emetic effects of palonosetron and aprepitant are needed to validate this interesting observation. Although some older women receiving dexamethasone for 3 days may experience improved control of delayed CINV, the potential additional benefit of taking dexamethasone for 3 days in older patients needs to be weighed against the increased risk for drug-drug interactions and problems with compliance in multiple-dosing regimens. Our findings may be also of help to clinicians who strive to reduce the total dexamethasone dose administered in patients who have relative contraindications against the use of corticosteroids.

Acknowledgements The authors would like to thank the clinicians, patients, nurses, and data managers who participated in the two trials.

Conflict of interest S. Sebastiani and T. Perrone are employees of Helsinn Healthcare and Italfarmaco S.p.A, respectively. L. Celio and M. S. Aapro have received consulting fees from Helsinn Healthcare. The authors have had full access to all the data in the study and thereby accept full responsibility for the integrity of the data and the accuracy of the data analysis.

Open Access This article is distributed under the terms of the Creative Commons Attribution Noncommercial License which permits any noncommercial use, distribution, and reproduction in any medium, provided the original author(s) and the source are credited.

\section{References}

1. Aapro M (2005) Optimising antiemetic therapy: what are the problems and how can they be overcome? Curr Med Res Opin 21:885-897. doi:10.1185/030079905x46313

2. Hesketh PJ (2008) Chemotherapy-induced nausea and vomiting. N Engl J Med 358:2482-2494

3. Roila F, Herrstedt J, Aapro M et al (2010) Guideline update for MASCC and ESMO in the prevention of chemotherapy- and radiotherapy-induced nausea and vomiting: results of the Perugia consensus conference. Ann Oncol 21(suppl 5):v232-v243. doi:10.1093/annonc/mdq194

4. Basch E, Prestrud AA, Hesketh PJ et al (2011) Antiemetics: American Society of Clinical Oncology clinical practice guideline update. J Clin Oncol 29:4189-4198. doi:10.1200/JCO.2010.34.4614

5. Celio L, Denaro A, Canova S, Gevorgyan A, Bajetta E (2008) Clinical update on palonosetron in the management of chemotherapy-induced nausea and vomiting. Tumori 94:447-452

6. Saito M, Aogi K, Sekine I et al (2009) Palonosetron plus dexamethasone versus granisetron plus dexamethasone for prevention of nausea and vomiting during chemotherapy: a double-blind, double-dummy, randomized, comparative phase III trial. Lancet Oncol 10:115-124. doi:10.1016/s1470-2045(08)70313-9

7. Vardy J, Chiew KS, Galica J, Pond GR, Tannock IF (2006) Side effects associated with the use of dexamethasone for prophylaxis 
of delayed emesis after moderately emetogenic chemotherapy. Br J Cancer 94:1011-1015. doi:10.1038/sj.bjc.6603048

8. Olver I, Molassiotis A, Aapro M, Herrstedt J, Grunberg S, Morrow G (2011) Antiemetic research: future directions. Support Care Cancer 19(suppl 1):s49-s55. doi:10.1007/s00520-010-1036-1

9. Aapro M, Fabi A, Nolè F, Medici M, Steger G, Bachmann C, Roncoroni S, Roila F (2010) Double-blind, randomised, controlled study of the efficacy and tolerability of palonosetron plus dexamethasone for 1 day with or without dexamethasone on days 2 and 3 in the prevention of nausea and vomiting induced by moderately emetogenic chemotherapy. Ann Oncol 21:1083-1088. doi:10.1093/annonc/mdp584

10. Celio L, Frustaci S, Denaro A et al (2011) Palonosetron in combination with 1-day versus 3-day dexamethasone for prevention of nausea and vomiting following moderately emetogenic chemotherapy: a randomized, multicenter, phase III trial. Support Care Cancer 19:1217-1225. doi:10.1007/s00520-010-0941-7

11. Teramukai S, Matsuyama Y, Mizuno S, Sakamoto J (2004) Individual patient-level and study-level meta-analysis for investigating modifiers of treatment effect. Jpn J Clin Oncol 34:717-721. doi:10.1093/jjco/hyh138

12. du Bois A, Vach W, Wechsel U, Holy R, Schaefer W (1996) 5Hydroxyindoleacetic acid (5-HIAA) and cortisol excretion as predictors of chemotherapy-induced emesis. Br J Cancer 74:1137-1140

13. Hursti TJ, Fredrikson M, Steineck G, Borjeson S, Furst CJ, Peterson C (1993) Endogenous cortisol exerts antiemetic effect similar to that of exogenous corticosteroids. Br J Cancer 68:112-114
14. Wilkinson CW, Petrie EC, Murray SR, Colasurdo EA, Raskind MA, Peskind ER (2001) Human glucocorticoid feedback inhibition is reduced in older individuals: evening study. J Clin Endocrinol Metab 86:545-550. doi:10.1210/jc.86.2.545

15. American Cancer Society. Breast cancer facts and figures 2009-2010. www.cancer.org/acs/groups/content/@nho/documents/document/ f861009final90809pdf.pdf Accessed 26 July 2011.

16. Jakobsen JN, Herrstedt J (2009) Prevention of chemotherapyinduced nausea and vomiting in elderly cancer patients. Crit Rev Oncol Hematol 71:214-221. doi:10.1016/j.critrevonc.2008.12.006

17. Warr DG, Street JC, Carides AD (2011) Evaluation of risk factors predictive of nausea and vomiting with current standard-of-care antiemetic treatment: analysis of phase 3 trial of aprepitant in patients receiving adriamycin-cyclophosphamide-based chemotherapy. Support Care Cancer 19:807-813. doi:10.1007/s00520010-0899-5

18. Yap K, Leong C, Chan A (2012) Controlling chemotherapyinduced nausea and vomiting with neurokinin-1 receptor antagonists in patients on AC-based chemotherapy - are we there yet? J Cancer Ther 3:90-102. doi:10.4236/jct.2012.31012

19. Feyer P, Jordan K (2011) Updated and new trends in antiemetic therapy: the continuing need for novel therapies. Ann Oncol 22:30-38. doi:10.1093/annonc/mdq600

20. Booth CM, Clemons M, Dranitsaris G, Joy A, Joung S, Callaghan W, Trudeau M, Petrella T (2007) Chemotherapy-induced nausea and vomiting in breast cancer patients: a prospective observational study. J Support Oncol 5:374-380 